\title{
Male mating success in the Azorean rock-pool blenny: the effects of body size, male behaviour and nest characteristics
}

\author{
R. F. Oliveira*q, J. A. Miranda †t, N. Carvalho†, E. J. Gonçalves*, \\ M. S. Grobert and R. S. SAntos† \\ *Unidade de Investigação em Eco-Etologia, Instituto Superior de Psicologia Aplicada, \\ Rua Jardim do Tabaco 34, 1149-041 Lisboa, Portugal; †Departamento de Oceanografia \\ e Pescas, Universidade dos Açores, 9901-862 Horta, Açores, Portugal and \\ $\$$ Life Sciences, Arizona State University West, 4701 W. Thunderbird Rd, Phoenix, \\ AZ 85069-7100, U.S.A.
}

(Received 16 February 2000, Accepted 7 July 2000)

\begin{abstract}
Larger male Azorean rock-pool blennies Parablennius sanguinolentus parvicornis received more female visits, were courted more often by females and received more spawnings. Larger males also received a higher number of male intrusions, attacked more conspecifics and defended larger territories. Larger males showed more nest cleaning behaviour and a marginally non-significant trend for higher egg fanning rate. Male courtship, male attack rate against conspecifics and parental behaviour were all correlated with the frequency of female spawnings received by each male even when controlling for male size, suggesting that these behaviour patterns influence male mating success. On the other hand, a positive partial correlation was found between female courtship and the frequency of female spawnings, controlling for the number of female visits, which suggests a role for female mate choice on male mating success. Finally, males nesting in chambers in the bottom of pools received more spawnings than males nesting either in crevices or under boulders. However, nest opening area was associated significantly negatively with male mating success, when controlling for male size. Thus, the present data suggest strongly that male characteristics overrule nest characteristics in determining male mating success in the Azorean rock-pool blenny.
\end{abstract}

(C) 2000 The Fisheries Society of the British Isles

Key words: sexual selection; blennies; female preferences; male competition.

\section{INTRODUCTION}

In resource-defence polygynous mating systems male fitness is assumed to be correlated positively with the quality of the resources held by the male and the ability of males to compete for and defend resources from competitors (Emlen \& Oring, 1977). In such mating systems female preferences should be based primarily on resource quality, particularly when those resources include parental care (Trivers, 1972). Hence, if the opportunity for female mate choice exists, it reinforces the effects of intrasexual selection. Thus, the variation found in mating success among nest-holder males in polygynous species can be explained by the variation in both male and nest-site quality. However, the best-quality nesting sites are occupied usually by high-quality males. That leads to a difficult distinction between the relative importance of the male and of the resource quality, when evaluating the partial contribution of the two for male breeding

ףAuthor to whom correspondence should be addressed. Fax: 35121 8860954; email: ruiol@ispa.pt 
success. For example, in a careful experiment Sikkel (1995) manipuated algal cover in the nests of the garibaldi Hypsipops rubicundus (Girard, 1854) and demonstrated that male courtship behaviour was influenced by nest-site quality, measured as the thickness of the algal mat. Nevertheless, there has been a considerable effort to assess the relative importance of male and nest-site quality for male reproductive success in polygynous teleost species. Male characteristics influencing the access to females include male body size (Downhower et al., 1983; Keenleyside et al., 1985; Thompson, 1986; Bisazza \& Marconato, 1988; Magnhagen \& Kvarnemo, 1989; Oliveira et al., 1999), courtship intensity (Schmale, 1981; Keenleyside et al., 1985; Torricelli et al., 1988) and parental abilities (Downhower \& Brown, 1980; Brown, 1981; Bisazza \& Marconato, 1988; Côté \& Hunte, 1989, 1993; Knapp \& Kovach, 1991; Forsgren, 1997) among others. Evidence exists also for the effect of territory quality (Jones, 1981; Sargent, 1982; Kodric-Brown, 1983; Thompson, 1986; Hastings, 1988a) or nest quality (i.e. presence of eggs in the nest: Marconato \& Bisazza, 1986; Unger \& Sargent, 1988; Kraak \& Videler, 1991; Kraak \& Groothuis, 1994; Santos, 1995) on male fitness. The relative importance of site and male quality varies undoubtedly among species according to mating system and type of parental care (Dugatkin \& Fitzgerald, 1997).

The rock-pool blenny Parablennius sanguinolentus (Pallas, 1811) is a benthic fish inhabiting the rocky shores of the Mediterranean and Atlantic (Zander, 1986), and is very abundant in the rocky intertidal of the Azores Islands (Santos et al., 1994). The taxonomic status of the Azorean population of this species is controverisial, with some authors considering it a separate species Parablennius parvicornis (Vallenciennes, 1836) (Zander, 1979). However, in a revision of the literature, Santos (1992) concluded that the available evidence could not support the existence of two separate species and proposed the existence of two sub-species, Parablennius sanguinolentus sanguinolentus and Parablennius sanguinolentus parvicornis in the Azores. In this species, during the breeding season, which lasts from May to August (Santos, 1989), the males defend a reproductive territory on which they prepare a nest in a natural crevice. The males court the females by signalling the location of the nest and circling and leading the females; spawning occurs inside the nest. The eggs are adhesive and are deposited on the inner surface of the nest. The males guard, clean and aerate the eggs until they hatch. Thus, this species exhibits a polygynic and polyandric mating system with exclusive male parental care (Santos, 1992; Santos \& Barreiros, 1993).

In the present paper the contributions of male and nest site characteristics are investigated relative to male mating success in the Azorean rock-pool blenny, using an observational approach.

\section{MATERIALS AND METHODS}

\section{STUDY SITE}

The study site was located in a flat basaltic intertidal platform at Feteira on the south coast of Faial Island, Azores (38 $31^{\prime} \mathrm{N} ; 28^{\circ} 27^{\prime} \mathrm{W}$ ) Rock intertidal pools are present in these type of platforms, resulting from the collapse of the top of lava tubes (furnas) due 
to erosion. Male P.s. parvicornis nest in these shallow rock pools (maximum depth $0.75 \mathrm{~m}$ ) under boulders or inside crevices (Santos, 1985).

\section{DATA COLLECTION}

Behavioural observations were conducted during low tide in June and July 1999. At high tide, strong wave action precluded observations. A total of $49 \mathrm{~h}$ of nest focal observations (sensu Martin \& Bateson, 1993) were conducted on 33 nests. Each observation lasted $20 \mathrm{~min}$ and on average three observations were made per nest on different days (mean observation time per nest was $86.5 \mathrm{~min}$, with a minimum of $20 \mathrm{~min}$ and a maximum of $180 \mathrm{~min}$ ). The distribution of the observations during the day ranged from 0933 to 1936 hours. In each observation the following variables were recorded: number of visits by conspecifics and the identity of the visitor (i.e. other nest-holder, floater, sneaker male, satellite male or female); details of all social interactions involving the nest-holding male, including agonistic and courtship behaviour given (male courtship is characterized by loop-swimming and leading the female to the nest) and received (female courtship is characterized by pectoral fin-flickering and opening and closing the mouth while presenting the flank in front of a nest, when a male is inside); and the identity of the intervenients. The following activities performed by the nest holder were recorded also: feeding, patrolling (i.e. an excursion out of the nest without feeding and without any intruder present); nest cleaning and egg fanning. The available ethogram for this species by Santos \& Barreiros (1993) was followed, in which a detailed description of the behaviour patterns can be found.

Nests were mapped and followed on a daily basis during the 2 months of the field work. Nest-holder males were recognized individually using a combination of individual marks (e.g. scars) and relative size differences.

To study the relationship between nest-holder male size, nest characteristics and mating success, the following variables were used.

(1) Body size. Male body size was not measured directly because nest-holder males were not captured before the observations, to avoid any disturbances. Their capture from inside the nests would require using an anaesthetic (e.g. quinaldine), which could affect the survival of the brood. Thus nest-holder males were classified by consensus among the observers into three size classes: extra-large (XL), large (L) and medium (M). This classification was validated $a$ posteriori by capturing a number of males previously allocated to one of the above-mentioned size classes and measuring their standard length. There were significant differences among the three classes considered [Kruskal-Wallis ANOVA: $H_{3,22}=15 \cdot 7, P=0 \cdot 001$; mean \pm S.D. $(n): \mathrm{XL}=12 \cdot 7 \pm 0 \cdot 6(6) ; \mathrm{L}=11 \cdot 6 \pm 1 \cdot 0$ (9); $\mathrm{M}=9 \cdot 3 \pm 0 \cdot 8$ (6); Dunn's multiple comparisons test $(P<0 \cdot 05): \mathrm{XL}>\mathrm{L}>\mathrm{M}]$.

(2) Nest site characteristics. Each nest was classified according to the following nest type-classes: type $\mathrm{A}=$ sand bottom cave; type $\mathrm{B}=$ chamber in the bottom; type $\mathrm{C}=$ under boulder, type $\mathrm{D}=$ crevice in vertical wall. Nest opening maximum width and height were taken to the nearest $\mathrm{mm}$ with a ruler. The approximate nest opening area was calculated by multiplying nest width by its height. Nest inner depth, which can be used as an indicator of nest size, was assessed by probing the nest with a flexible string and measuring the maximum length of string inserted inside the nest. Nest depth was defined as the distance from the topside of the nest to the hydrographic zero. This distance was measured, while recording the exact time, with a tape measure, from the top of the nest to the water surface. Later a tide table was used to compute the distance to the hydrographic zero (Instituto Hidrográfico, 1999). Distance to the nearest neighbour was taken also with a measuring tape to the nearest $\mathrm{cm}$ as the shortest line between the focal nest and its closest nest openings. The average patrolling distance (i.e. the mean of the maximum distances that the nest-holder male moved away from the nest during patrolling excursions) was used as an indicator of territory size.

(3) Mating success. Because of the topographical complexity of the nesting cavities, the percentage of nest surface covered with eggs could not be evaluated with confidence. Thus, the number of observed female spawnings in each nest was used as a measure of male mating success. Operationally, a spawning episode was defined as any female entrance into the nest in which the female stayed for more than $30 \mathrm{~s}$. In several of these 
instances females lay with their bellies against the nest wall and quivered. Thus, the chances that the female nest entrances that were counted were not spawnings is low, because when females enter a nest for other purposes (e.g. egg cannibalism) they are attacked promptly by the nest-holder male.

\section{DATA ANALYSIS}

Some variables violated the assumptions of parametric statistics so non-parametric tests were used. All tests were two-tailed.

To assess the importance of body size on mating success of nest holding males, the number of spawnings that occurred in nests of males of different size classes (i.e. XL, L and $\mathrm{M}$ ) were compared. Also, the number of female visits and female courtship acts directed towards nesting males were compared as well as sneaking attempts and the behaviour of the nest-holder males.

To determine the importance of nest type on the mating success of nest holding males, the number of spawnings that occurred in each of the classes of nest type were compared. The behaviour of males nesting in different nest types and the number of female visits, sneaking attempts and female courtship acts received by males of different nest type classes, were analysed also.

To investigate the potential relationship between nest type and male body size simulation statistics were applied to the analysis of contingency tables to avoid the problem of increasing type I errors (ACTUS, Estabrook \& Estabrook, 1989). Spearman rank correlations were employed when appropriate.

To assess the relative importance of nest characteristics on male mating success, Kendall rank-order partial correlations were computed between the frequency of female spawnings and each nest characteristic while controlling for nest-holder body size.

To investigate potential effects of male behaviour on male mating success Kendall rank-order partial correlations were computed between a set of male behaviours and the frequency of female spawnings received by each male.

The significance of the Kendall rank-order partial correlation coefficients was determined using the critical values given in Siegel \& Castellan (1988).

All the statistical procedures were run on the software package Statistica v.5.0A (Statsoft Inc., U.S.A.).

\section{RESULTS}

Larger males received a significantly higher number of both female visits and female courtship acts which resulted in a higher number of spawnings (Table I). Male courtship was significantly higher in XL males than in L males while $\mathrm{M}$ males showed intermediate levels of courtship (Table I). Larger males also received a significantly higher number of conspecific visits, were involved in a higher number of attacks towards conspecifics and defended larger territories. Concerning parental behaviour, larger males presented a non-significant trend for more fanning behaviour and had significantly higher levels of nest cleaning behaviours (Table I). There were no significant differences in the number of sneaking attempts suffered by nest holding males of the different size classes (Table I).

Although the number of female visits to different nest types did not differ significantly, type B nests received more female courtship acts and spawnings (Table II). There were no significant behavioural differences among males nesting on different nest types except for the frequency of nest cleaning behaviour, which was significantly higher in males nesting in type B nests. Both territory size and the number of sneaking attempts suffered were not significantly different among nest type classes also (Table II). Several nest physical 


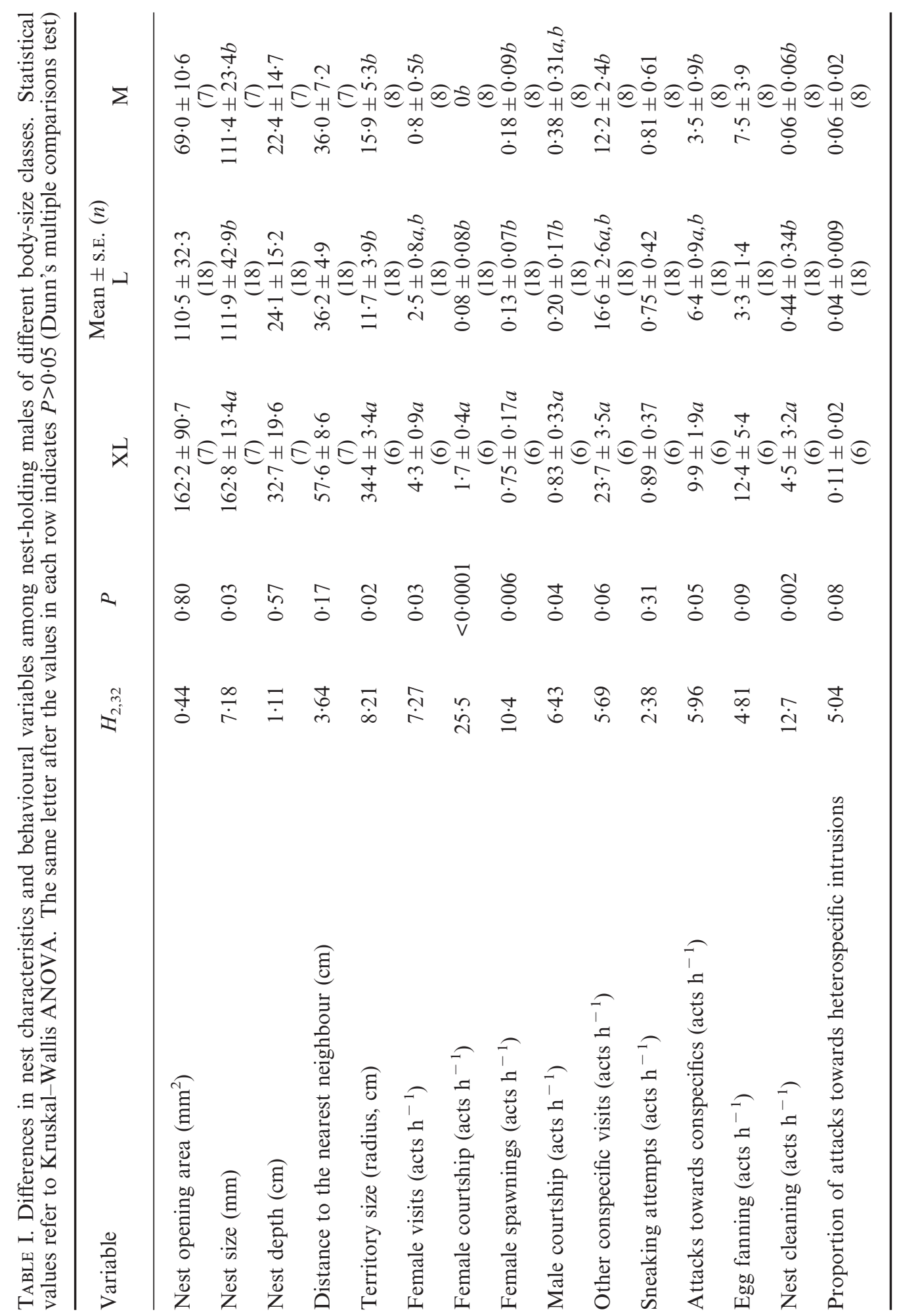




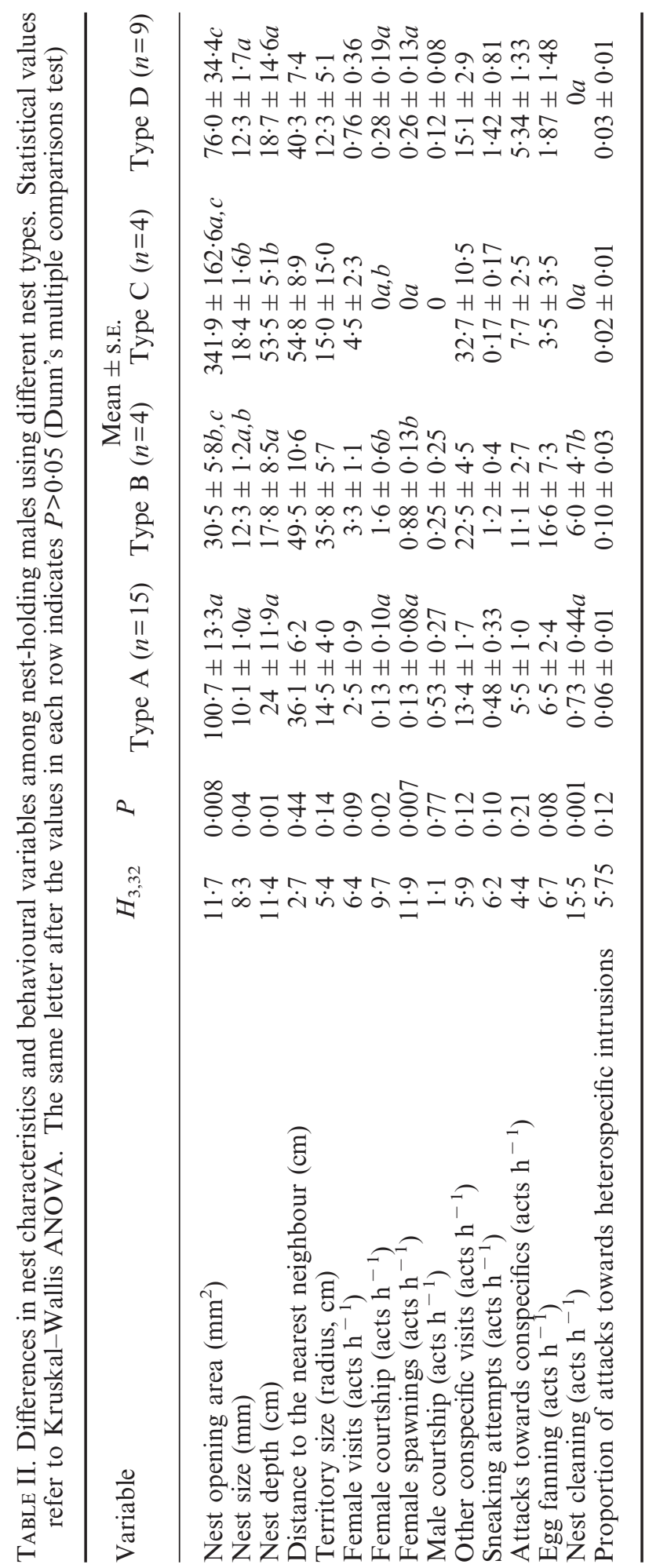


TABLE III. Relationship between male body size and nest type used in breeding males of P.s. parvicornis (ACTUS: $\chi_{6}^{2}=13 \cdot 5$, $P=0.04)$

\begin{tabular}{|c|c|c|c|c|}
\hline \multirow{2}{*}{$\begin{array}{l}\text { Male } \\
\text { body size }\end{array}$} & \multicolumn{4}{|c|}{ Nest type } \\
\hline & Type A & Type B & Type C & Type D \\
\hline XL & 1 & 3 & 1 & 1 \\
\hline $\mathrm{L}$ & 8 & 0 & 3 & 7 \\
\hline M & 5 & 1 & 0 & 1 \\
\hline
\end{tabular}

TABLE IV. Kendall rank-order partial correlations $\left(\tau_{\mathrm{xy}, \mathrm{z}}\right)$ between a set of nest characteristics $(x)$ and the frequency of female spawnings in each nest $(y)$ controlling for nest-holder body size $(z)(n=32)$

\begin{tabular}{lcc}
\hline Nest characteristic & $\tau_{\mathrm{xy}, \mathrm{z}}$ & $P$-value \\
\hline Nest opening area & $-0 \cdot 28$ & $<0.05$ \\
Nest size & $-0 \cdot 05$ & N.S. \\
Nest depth & $-0 \cdot 15$ & N.S. \\
Distance to the nearest neighbour & $-0 \cdot 02$ & N.S. \\
Territory size & $0 \cdot 12$ & N.S. \\
\hline
\end{tabular}

All non-significant results (N.S.) have $P>0 \cdot 20$.

characteristics were correlated with the behavioural activities displayed at nest. Nest-opening area was correlated negatively with the number of spawnings $\left(n=32\right.$ nests, $\left.r_{\mathrm{s}}=-0.35, P<0 \cdot 05\right)$ while nest inner depth was correlated positively with female courtship $\left(n=32\right.$ nests, $\left.r_{\mathrm{s}}=0.47, P<0 \cdot 01\right)$ and the number of conspecific male visits $\left(n=32\right.$ nests, $\left.r_{\mathrm{s}}=0 \cdot 53, P<0 \cdot 01\right)$.

The distribution of males of different size classes by different nest types was not random (Table III). Nest types A, C and D were occupied to a large extent by $\mathrm{L}$ males and nest type B by XL males. Although there were no significant differences among different male size classes concerning nest opening area (Kruskal-Wallis ANOVA for nest opening area by male body size class: $H_{2,32}=0.44, \quad P=0.80$ ) larger males defended larger nests (Kruskal-Wallis ANOVA for nest size by male body size class: $H_{2,32}=7 \cdot 18, P=0 \cdot 02$; Dunn multi-comparison test $(P<0 \cdot 05)$ : $\mathrm{XL}$ males $>\mathrm{L}$ males $=\mathrm{M}$ males $)$. Thus, the differences in mating success among nest types could be due to the variation in body size of the males adopting them. Moreover, no significant effects of nest characteristics on male mating success were found when controlling for the effect of nest-holder body size (Table IV).

Male courtship and parental care behaviour (i.e. egg fanning and nest cleaning) were associated significantly with a higher frequency of female spawnings received by nest-holder males, even when controlling for variation in body size among males (Table V). Male courtship was associated significantly with the 
TABLE V. Kendall rank-order partial correlations $\left(\tau_{\mathrm{xy}, \mathrm{z}}\right)$ between a set of male behavioural traits $(x)$ and the frequency of female spawnings $(y)$ in each nest controlling for nest-holder body size $(z)(n=33)$

\begin{tabular}{lrc}
\hline Male behaviour & $\tau_{\mathrm{xy}, \mathrm{z}}$ & $P$-value \\
\hline Male courtship & 0.51 & $<0.001$ \\
Egg fanning & 0.38 & $<0.005$ \\
Nest cleaning & 0.41 & $<0.001$ \\
Attacks towards conspecifics & 0.38 & $<0.005$ \\
Attacks towards heterospecifics & -0.08 & N.S. \\
\hline
\end{tabular}

All non-significant results (N.S.) have $P>0 \cdot 20$.

frequency of female spawnings even when controlling for the frequency of female visits received by each male (Kendall rank-order partial correlation: $\tau_{\mathrm{xy} . \mathrm{z}}=0 \cdot 46$, $n=33, P<0 \cdot 001)$.

Also, female behaviour seems to be an important factor determining male mating success, as is suggested by the significant positive association between the frequencies of female courtship and female spawnings at each nest, when controlling for the number of female visits (Kendall rank-order partial correlation: $\left.\tau_{\mathrm{xy} . \mathrm{z}}=0 \cdot 44, n=33, P<0 \cdot 001\right)$.

\section{DISCUSSION}

The data suggest that male characteristics are more important factors determining male mating success than are nest-site characteristics in the Azorean rock-pool blenny. Apart from the nest-opening area, none of the other nest characteristics were associated with male mating success when controlling for male size. Because male size is correlated also with male competitive ability, these results suggest that the males compete for the better nesting sites and that females use male clues, not nest-site characteristics, when looking for prospective mates.

The nest-opening area was associated negatively with frequency of female spawnings. In blenniids usually males use nests that fit their body size tightly. That enables better defence of the nest against potential intruders, both conspecific competitor males and heterospecific nest predators (e.g. Lypophrys spp., Kotrschal, 1988). Thus, females may benefit directly, in terms of reduced egg predation, by choosing males nesting in nests with a narrow entrance.

On the other hand, a number of male characteristics appeared to be associated with the frequency of spawnings received by each male. These are body size, male courtship, male parental behaviour (i.e. egg fanning and nest cleaning) and the frequency of attacks towards conspecifics.

Both male courtship and the frequency of attacks against conspecifics can be viewed as indicators of male sexual motivation, which would confer on them an advantage both in terms of male-male competition and on inter-sexual selection. The significant effect of attack frequency towards conspecifics also reinforces the 
hypothesis that male $P$. s. parvicornis compete actively for nest sites in this population. Thus, male-male competition should be viewed as playing an important role in sexual selection. However, the effects of female mate choice should not be ruled out because female courtship behaviour also had a major influence on male mating success, even when controlling for the frequency of female visits. Therefore these results suggest strongly active female mate choice.

Bigger males received more female visits and more female courtship acts which resulted in more spawnings. XL males had a mating success $c$. 5 times higher $(0.75$ v. 0.15$)$ than that of the other males (i.e. L and M combined). A large body of literature suggests the occurrence of female mate preferences for larger males in species with male parental care including blennioids (Thompson, 1986; Hastings, 1988a, b; Petersen, 1988; Côte \& Hunte, 1989; Oliveira et al., 1999). However, the multiple regression analysis suggests that male size per se might not be the key variable for female mate choice because it is excluded from the stepwise model and, by itself it explains only a small proportion of the variation observed in male mating success (univariate $r^{2}=0 \cdot 13$ ). Nonetheless, male size may be under indirect female mate choice because it is associated with other variables that explain better the variation observed in female spawnings that each nest received, namely male parental behaviour (i.e. egg fanning and nest cleaning) and male courtship. Thus, in this species females may have a preference for male parental abilities or for more vigorous males as assessed by male courtship intensity, which is more intense in larger males.

Female preference for parental abilities has been demonstrated in other teleost species with extensive parental care (Dugatkin \& Fitzgerald, 1997) and larger males are probably better parents (e.g. mottled sculpins Cottus bairdi Girard, 1850; Downhower et al., 1983). In P. s. parvicornis, larger males tend to be more effective against heterospecific intruders which could be potential egg raiders.

Female choice for visual-display behaviour occurs in a larger number of species from invertebrates (e.g. fiddler crabs, Latruffe et al., 1999) to birds (e.g. widowbirds, Andersson, 1991). However, in fishes there is a lack of evidence for visual display based female mate choice, partially due to the interdependence between male and female behaviour (Houde, 1997). The present study controlled for this causal uncertainty by calculating the association between the frequency of male courtship behaviour and the number of female spawnings received by males while controlling for the frequency of female visits each male received. Thus, potential flaws in the causal relationship between male display and female behaviour do not contaminate the association found between male courtship and mating success. In a number of other teleost species, females use male courtship intensity as a mate choice criterion (Karino, 1995; Grant \& Green, 1996; Rosenthal et al., 1996; see Andersson, 1994 and Houde, 1997 for a further discussion of this issue). Female preference for courtship vigour can bring them either direct or indirect benefits. Knapp \& Kovach (1991) demonstrated that courtship intensity is a reliable indicator of male parental investment in the bicolour damselfish Stegastes partitus (Poey, 1868). Male vigour could be associated also with male genetic quality, and thus females that mate preferentially with males that court them more intensely may benefit indirectly in terms of offspring viability (Reynolds \& Gross, 1992). 
Although there were significant differences in the number of female visits to different nests, according to nest-holder male size, those differences were of a smaller magnitude than the ones found for female courtship. This indicates that there is a differential proportion of visiting females that court males of different sizes. No females were observed courting $\mathrm{M}$ males, whereas the majority courted XL males. However, spawnings with $\mathrm{M}$ males did occur, without female courtship. These results suggest female competition for access to larger males and that female courtship may also serve to inhibit male aggression during the initial phases of the spawning sequence, which would not be necessary when spawning with less choosy smaller mates. Thus, the potential occurrence of mate choice by larger nesting males exists in $P$. s. parvicornis also.

Moreover, if the frequency of male courtship is divided by the number of female visits received by the males of different size classes, a clear picture emerges. On average, $M$ males courted half of the females that visited them, while larger males courted $1 / 8$ of the visiting females, which again suggests that $\mathrm{M}$ males were either more motivated to mate or were less choosy. Intermediatesize males suffered more body injuries than smaller and larger males, pointing to higher competition among the males of this size class (Santos \& Nash, 1996).

Sneaking rate (i.e. frequency of sneaking attempts per female spawning) indicates that smaller males are under a higher pressure than XL males. There was one sneaking attempt per successful spawning in XL males while in smaller males there were $c$. five sneaking attempts per successful spawning. This might be the result of smaller males being less aggressive than XL males. Thus, an additional benefit for females to spawn in XL male nests is to avoid mating interferences by other males, which may disrupt spawning (Sheppey \& Ribbink, 1985).

In conclusion, both intrasexual selection, in the form of male-male competition for nesting sites, and female mate choice may determine the variation found in male mating success in $P$. s. parvicornis. Female mate choice may be based on direct benefits by choosing better fathers or on indirect benefits by choosing more vigorous males that may father offspring of higher viability. Further experimental studies are needed to disentangle the potential roles of these hypotheses for explaining sexual selection in the rock-pool blenny.

The authors thank P. Lourinho (PRAXIS XXI, BTI/17123/98) and N. Serpa for providing help and technical support during the field work and C. Magnhagen and two anonymous referees for the improvement of the manuscript. This study is part of a project funded by Fundação para a Ciência e a Tecnologia and FEDER (PRAXIS XXI, PCNA/BIA/94/96).

\section{References}

Andersson, S. (1994). Sexual Selection. Princeton, NJ: Princeton University Press.

Andersson, S. (1991). Bowers on the savanna: display courts and mate choice in a lekking widowbird Euplectes jacksoni. Behavioral Ecology 2, 210-218.

Bisazza, A. \& Marconato, A. (1988). Female mate choice, male-male competition and parental care in the river bullhead, Cottus gobio L. (Pisces, Cottidae). Animal Behaviour 36, 1352-1360.

Brown, L. (1981). Patterns of female choice in mottled sculpins (Cottidae, Teleostei). Animal Behaviour 29, 375-382. 
Côté, I. M. \& Hunte, W. (1989). Male and female mate choice in the redlip blenny: why bigger is better. Animal Behaviour 38, 78-88.

Côté, I. M. \& Hunte, W. (1993). Female redlip blennies prefer older males. Animal Behaviour 46, 203-205.

Downhower, J. F. \& Brown, L. (1980). Mate preferences of female mottled sculpins, Cottus bairdi. Animal Behaviour 28, 728-734.

Downhower, J. F., Brown, L., Pederson, R. \& Staples, G. (1983). Sexual selection and sexual dimorphism in mottled sculpins. Evolution 37, 96-103.

Dugatkin, L. A. \& Fitzgerald, G. J. (1997). Sexual selection. In Behavioral Ecology of Teleost Fishes (Godin, J. G., ed.), pp. 266-291. Oxford: Oxford University Press.

Emlen, S. T. \& Oring, L. W. (1977). Ecology, sexual selection, and the evolution of mating systems. Science 197, 215-223.

Estabrook, C. B. \& Estabrook, G. F. (1989). ACTUS: a solution for the problem of small samples in the analysis of two-way contingency tables. Historical Methods 22, 5-8.

Forsgren, E. (1997). Females and gobies prefer good fathers over dominant males. Proceedings of the Royal Society of London B 264, 1283-1286.

Grant, J. W. A. \& Green, L. D. (1996). Mate copying versus preference for actively courting males by female Japanese medaka (Oryzias latipes). Behavioral Ecology 7, 165-167.

Hastings, P. A. (1988a). Female choice and male reproductive success in the angel blenny, Coralliozetus angelica (teleostei: Chaenopsidae). Animal Behaviour 36, $115-124$.

Hastings, P. A. (1988b). Correlates of male reproductive success in the browncheek blenny, Acanthemblemaria crockeri (Blennioidea: Chaenopsidae). Behavioral Ecology and Sociobiology 22, 95-102.

Houde, A. E. (1997). Sex, Color, and Mate Choice in Guppies. Princeton, NJ: Princeton University Press.

Instituto Hidrográfico. (1999). Tabela de Marés 1999, Vol. I. Lisboa: Instituto Hidrográfico.

Jones, G. P. (1981). Spawning-site choice by female Pseudolabrus celidotus (Pisces: Labridae). Behavioral Ecology and Sociobiology 8, 129-142.

Karino, K. (1995). Male-male competition and female mate choice through courtship display in the territorial damselfish, Stegastes nigricans. Ethology 100, 126-138.

Keenleyside, M. H. A., Rangeley, R. W. \& Kuppers, B. U. (1985). Female mate choice and male parental defence behaviour in the cichlid fish Cichlasoma nigrofasciatum. Canadian Journal of Zoology 63, 2489-2493.

Knapp, R. A. \& Kovach, J. T. (1991). Courtship as an honest indicator of male parental quality in the bicolor damselfish, Stegastes partitus. Behavioral Ecology 2, 295-300.

Kodric-Brown, A. (1983). Determinants of male reproductive success in pupfish (Cyprinodon pecosensis). Animal Behaviour 31, 128-137.

Kotrschal, K. (1988). Blennies and endolithic bivalves: differential utilization of shelter in Adriatic blenniidae (Pisces: Teleostei). Marine Ecology (PSZNI) 9, 253-269.

Kraak, S. B. M. \& Groothuis, T. G. G. (1994). Female preference for nests with eggs is based on the presence of the eggs themselves. Behaviour 131, 189-206.

Kraak, S. B. M. \& Videler, J. J. (1991). Mate choice in Aidablennius sphynx (Teleostei, Blenniidae); females prefer nests containing more eggs. Behaviour 119, 243-266.

Latruffe, C., McGregor, P. K. \& Oliveira, R. F. (1999). Visual signalling and sexual selection in male fiddler crabs Uca tangeri. Marine Ecology Progress Series 189, 233-240.

Magnhagen, C. \& Kvarnemo, L. (1989). Big is better: the importance of size for reproductive success in male Pomatochistus minutus (Pallas) (Pisces, Gobiidae). Journal of Fish Biology 35, 755-763.

Martin, P. \& Bateson, P. (1993). Measuring Behaviour: an Introductory Guide, 2nd edn. Cambridge: Cambridge University Press. 
Marconato, A. \& Bisazza, A. (1986). Males whose nests contain eggs are preferred by female Cottus gobio. Animal Behaviour 34, 1580-1582.

Oliveira, R. F., Almada, V. C., Forsgren, E. \& Gonçalves, E. J. (1999). Temporal variation in male traits, nesting aggregations and mating success in the peacock blenny. Journal of Fish Biology 54, 499-512.

Petersen, G. W. (1988). Male mating success, sexual size dimorphism and site fidelity in two species of Malacoctenus (Labrisomidae). Environmental Biology of Fishes 21, 173-183.

Reynolds, J. D. \& Gross, M. R. (1992). Female mate preference enhances offspring growth and reproduction in a fish, Poecilia reticulata. Proceedings of the Royal Society of London B 250, 57-62.

Rosenthal, G. G., Evans, C. S. \& Miller, W. L. (1996). Female preference for dynamic traits in the green swordtail, Xiphophorus helleri. Animal Behaviour 51, 811-820.

Santos, R. S. (1985). Parentais e satélites: tácticas alternativas de acasalamento nos machos de Blennius sanguinolentus Pallas (Pisces: Blenniidae). Arquipélago, Life and Earth Sciences 6, 119-146.

Santos, R. S. (1989). Observações sobre os intervalos de desenvolvimento de Parablennius sanguinolentus (Pallas) (Pisces: Blenniidae) dos Açores: períodos embrionáo, larvar e juvenil. Arquivos do Museu Bocage 19, 293-310.

Santos, R. S. (1992). Behavioural Ecology, Phenology and Ethology of an Intertidal Blenny, Parablennius sanguinolentus parvicornis (Valenciennes in Cuvier \& Valenciennes 1836) (Pisces: Blenniidae), from the Azores. PhD thesis, University of Liverpool.

Santos, R. S. (1995). Allopaternal care in the redlip blenny. Journal of Fish Biology 47, 350-353.

Santos, R. S. \& Barreiros, J. P. (1993). The ethogram of Parablennius sanguinolentus parvicornis (Pisces: Blenniidae) of the Azores. Arquipélago, Life and Marine Sciences 11A, 73-90.

Santos, R. S. \& Nash, R. D. M. (1996). Seasonal variations in injuries suffered by individuals of the Azorean rock-pool blenny, Parablennius sanguinolentus parvicornis. Copeia 1996, 216-219.

Santos, R. S., Nash, R. D. M. \& Hawkins, S. J. (1994). Fish assemblages on intertidal shores of the island of Faial, Azores. Arquipélago, Life and Marine Sciences 12, 87-100.

Sargent, R. C. (1982). Territory quality, male quality, courtship intrusions, and female nest-choice in the three-spined stickleback, Gasterosteus aculeatus. Animal Behaviour 30, 364-374.

Schmale, M. C. (1981). Sexual selection and reproductive success in males of the bicolor damselfish, Eupomacentrus partitus (Pisces: Pomacentridae). Animal Behaviour 29, $1172-1184$.

Sheppey, K. \& Ribbink, A. J. (1985). Mating interruption, an alternative to sexual selection in cichlid fish. South African Journal of Science 81, 702.

Siegel, S. \& Castellan, N. J. Jr (1988). Nonparametric Statistics for the Behavioral Sciences, 2nd edn. New York: McGraw Hill.

Sikkel, P. C. (1995). Effects of nest quality on male courtship and female spawning-site choice in an algal-nesting damselfish. Bulletin of Marine Science 57, 682-689.

Thompson, S. (1986). Male spawning success and female choice in the mottled triplefin, Forsterygion varium (Pisces: Tripterygiidae). Animal Behaviour 34, 580-589.

Torricelli, P., Parmigiani, S., Lugli, M. \& Gandolfi, G. (1988). Intermale aggression in Padogobius martensi (Günther) (Pisces Gobiidae): effect of size and prior residence. Monitore Zoologico Italiano 22, 121-131.

Trivers, R. L. (1972). Parental investment and sexual selection. In Sexual Selection and the Descent of Man (Campbell, B., ed.), pp. 136-179. Chicago: Aldine.

Unger, L. M. \& Sargent, R. C. (1988). Allopaternal care in the fathead minnow Pimephales promelas: females prefer males with eggs. Behavioral Ecology and Sociobiology 23, 27-32. 
Zander, C. D. (1979). Morphologische und ökologische Untersuchung der Schleimfische Parablennius sanguinolentus (Pallas 1811) und P. parvicornis (Vallenciennes 1836) (Perciformes, Blenniidae). Mitteilungen des Hamburgische Zoologische Museum Institut 76, 469-474.

Zander, C. D. (1986). Blenniidae. In Fishes of the North-eastern Atlantic and the Mediterranean, Vol. 3 (Whitehead, P. J. P., Bauchot, M.-L., Hureau, J.-C., Nielsen, J. \& Tortonese, E., eds), pp. 1096-1112. Paris: UNESCO. 